\title{
The sound of mineral stone: Chemical properties of civilisation
}

\author{
MOON Martina Zelenika \\ Independent interdisciplinary artist \\ Address: Ivekovićeva 21, 10000 Zagreb Croatia \\ E-mail: info@martinazelenika.com Web: www.martinazelenika.com
}

\begin{abstract}
This paper examines the result of a laboratory analysis of mineral stones with metal properties that have had an impact on raising today's civilisation. Through the artistic prism of intuitive perceptions and factual scientific analyses, in this case I present the process of creation of my research based art project New Europe and its poetic outcome from a scientific analysis of mineral stones. The project reflects the Change phenomenon, visibly - large geomorphic reliefs covered with mineral stones and Dark matter (unmaterial dimension of stones) shown audibly - two types of transmission of X-ray analysis into sound - music. How do mineral stones sound? The combination of reliefs, mineral stones and sounds creates a unique blend of material and energetically beneficial. The presentation focuses on the process of transmission involved from one medium to another, primarily on possibilities of the poetic outcome of scientific analyses sonified X-ray data.
\end{abstract}

Keywords: X-ray, crystallography, laboratory analysis, mineral stones, data sonification, data processing, software, sound art, visual art, reliefs1. Introduction

\section{INTRODUCTION}

Sound is a medium used in this project to reveal the unmaterial dimensions of stones - dark matter from a material object. Mineral stones used in the project possess metal properties which have a great impact in making todays civilisation in terms of its chemical aspect. The paper examines a very important phenomenon which exists without any change in its condition. The process of creation is implemented through every level of this topic, including the creation of Earth, civilisation, artistic projects, and techniques of transmission from one media to another. The process of creation is closely related to the Change phenomenon as an absolute ubiquitous constant in the Universe. The main key of human evolution is creativity and imagination as tools for surviving. Naturally, human evolution is the outcome of the genes from our ancestors. Similar to this fact Oxford professor and British Academy fellow, Timothy Williamson, gave an explanation in the New York Times philosophy blog, The Stone titled Reclaiming the Imagination in 2010. Today, humans can use these tools for different purposes such as a contribution to Art and Science for example. The artistic project titled New Europe presented in this paper reflects the time we live in when technology, science, medicine, astronomy, art and knowledge has evolved. After the process of creation and humans evolved imagination, the paper examines a similar example of sonified X-ray data. The use of $X$-ray data sonification has been published in 2011 which deals with a different type
- a sonification of astronomical X-ray from the author Wanda Diaz Merced. Her doctoral project was published on Harvard's web page under the title Star Songs - from X-rays to music.

For the purpose of the realisation of the New Europe project, in collaboration with Ruđer Bošković Institute Zagreb in 2017, quantum mechanics were used for various analyses:

1) X-ray powder diffraction (XRPD) which deals with particle analysis, determination of chemical and crystallographic properties.

2) a high-resolution scanning electron
microscope FESEM.

Natural mineral stones are: gold Pyrite (FeS2), silver Galena ( $\mathrm{PbS}$ ) and black Sphalerite (ZnS). These minerals were used for further processing into sound. Digitally obtained data has been converted into two different types of transmission. One is a software that produces sound from the image called Photo Sounder made by a software maker Michel Rouzic, and the other is Musical Algorithm made by Professor Jonathan M. Middelton. The outcome from the Photo Sounder is a deep frequency sound and from the Musical Algorithm the sound is rendered in a piano version. The sounds, ie music from the Musical Algorithm, result in an aleatoric music in which some element of the composition is left to chance. Although everything is left to chance, the music sounds partly harmonious and meaningful. When put 
together, deep frequency sound and piano version, the result is almost a meditative experience of a relatively harmonious but abstract music. My aim is to make you aware of these stones and their essential role in our existence and whole civilisation. We are all connected materially and unmaterially to mineral stones as a result of the mutation of stardust. The realization of my research based art project titled New Europe is multilayered. I realised this project by arriving to a poetic outcome from a scientific analysis of mineral stones - sonifed X-ray data.

\section{A PROCESS OF CREATION}

The cause of two objects colliding and changing each others chemical properties such as meteorites crashing on planets and causing a shift in the climate over extended periods of time has truly marked our planet. Through millions of years of many external crashes and depressions, vast changes in temperature, environment, geomorphic creation, the soil of the Planet became rich. Magical properties of meteorites have crossed cultures through history.

Beautifully described in one sentence from the internet article Splitting the heavens: 4 real swords made of meteorites (2015) from the author Kruse C. (1)

"Legends are saturated with fables of powerful weapons forged from the stars."

Meteoric swords aren't just a myth. The examples of extraordinary swords from the list selection of Kruse C. such as Attila the Hun's fabled Sword of Mars and the Japanese katana Tentetsuou or The Sword of Heaven - as The Chiba Institute of Technology where it is on display writes: "...the Sword of Heaven truly symbolizes the relationship between human technology and space." (2)

All these legends, history of the human civilisation was built on wars, lives and deaths, conquering territories and seizing power. The earliest historical example of a meteoric blade is the dagger found in the tomb of Tutankhamun - which was found in 1925 and dates back to over 3000 years.

Change is unescapable and we are all evolving through actions of change. It is a matter of time when we will be more aware of the environment and our consequences.

\section{THE EVOLUTION OF IMAGINATION}

Every creation and imagination starts with inspiration as an individual experience of thoughts and surroundings. We are on the path of one major phenomenon - the Change phenomenon. The Change in its structure belongs to the absolute constant and it shows no change in conditions.

Fisher M. (internet article Why We Did Evolve Imagination? 2010) addresses the Oxford professor and British Academy fellow Timothy Williamson who gives us an explanation in the New York Times philosophy blog, The Stone titled Reclaiming the Imagination (2010). For what purpose did we evolve our imaginations, which have come to guide so much of human culture? He agrees with Williamsons argument that imagination is an essential tool for survival, but a poorly developed imagination could lead people into potentially deadly situations. Therefore, those of our ancestors with the sharpest and most precise imaginative abilities would be the most likely to have survived and passed on their genes. (3)

Timothy Williamson claims that in science, the obvious role of imagination is in the context of discovery:

“Unimaginative scientists don't produce radically new ideas. But even in science imagination plays a role in justification too. Experiment and calculation cannot do all its work." (4)

The use of imagination is a constant phenomenon with passing centuries. Imagination and creativity drive human evolution.

Characteristics of the creative approach used in the project New Europe are a fusion of urge, intuition and facts, combined with laboratory analyses and scientific methods, resulting in a poetic-scientific outcome. The project reflects the state of our human evolution (and my personal evolution) in relations to discoveries and knowledge including:

science, technology and environmental conditions.

Through the artistic prism of intuitive perceptions and factual scientific analyses, the project represents the phenomenon of dark matter shown audibly - two types of transmission of X-ray analysis into sound ie music, and the Change phenomenon shown visibly - large geomorphic reliefs covered with mineral stones.

\subsection{New Europe - visual and material aspects}

Beautifully made reliefs reflect the visualisations of the impact of Change phenomenon presented as organic-geomorphic surfaces of the Planet. The project consists of three (3) reliefs, two diptychs and one triptych.

The diptych, New Europe shows impacts on Earth from the outside, from space such as craters formed by meteorites crashing on our planet. This 
represents external depression. The surface of the relief is covered with dust and small pieces of Gold Pyrite mineral stone.

Gold Pyrite FeS2 (fake gold, gold for fools) mineral stone is technically known as iron sulfide and is one of the most common sulfide minerals. In recent times, a group of MIT researchers and the University of California have been taking another approach to developing iron pyrite for solar energy; the surface "energy bandgap," of pyrite, a property essential for making solar cells or semiconductor devices.

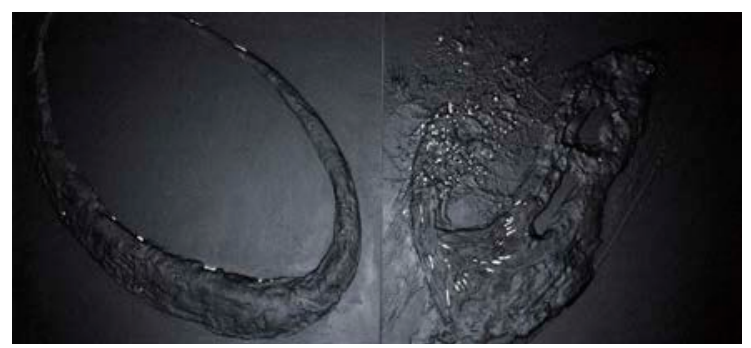

Figure 1: The diptych, relief New Europe (2016)

The diptych, Whip of God represents the tectonic changes of Earth, an internal change. Its surface is covered with a dust and small pieces of Silver Galena mineral stone.

Silver Galena PbS mineral stone is a cubic stone that is made of lead minerals. This mineral has been mined for thousands of years due to its lead and silver content. Galena is usually located in Germany, United Kingdom, Peru, and the USA.

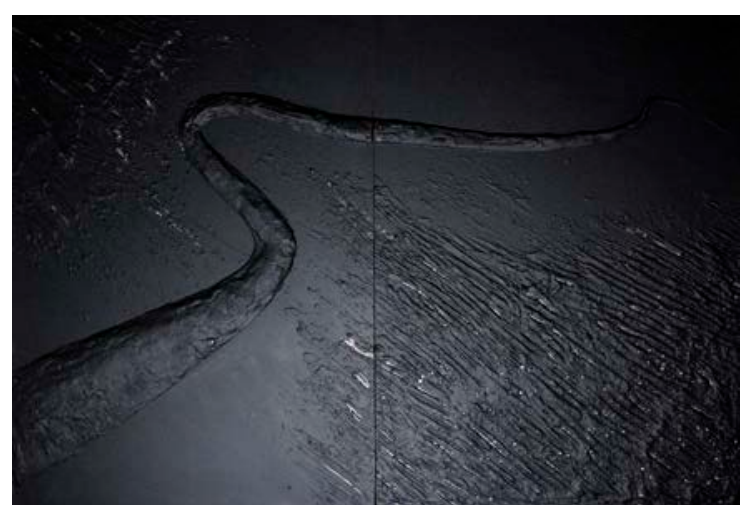

Figure 2: The diptych, relief Whip of God (2016)

The triptych Rebirth of the Earth reflects three different types of surfaces caused by inner or external physical influences. Its surface is covered with dust and small pieces of Black Sphalerite mineral stone.

Black Sphalerite is a mineral that consists largely of zinc sulfide in crystalline form, but it almost always contains variable amounts of iron. From the energetic aspect, this very interesting crystal will help you harmonize your female and male aspects while also unleashing your creativity.

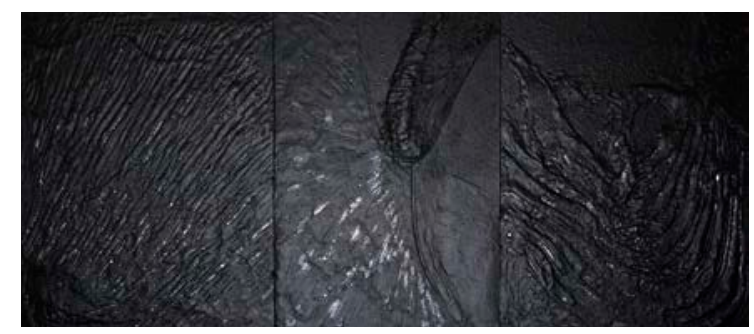

Figure 3: The diptych, relief Rebirth of the Earth (2016)

All these three (3) minerals are energetically good for lower chakras and will help you to be more grounded, stable and find your own power. It helps you evolve more daily but it is necessary to use them in the right way.

\subsubsection{Sonified X-ray data}

What is Sonification? Sonification means to display data as sound or non-speech audio.

Sonification as a scientific tool: the scientific use of sonification has the goal of discovering meaning in sounds. Sonification intends to help recognize patterns or regularities underneath seemingly random X-ray data presented as sounds. In this case, X-ray analysis has been converted through two (2) different digital tools for audio readings which contributes to advancing scientific knowledge.

In relation to the sonification of X-ray was found one and a very specific example which deals with sonification of astronomical X-ray data. A doctoral project was published on Harvard's internet web page called Star Songs - from X-rays to music;

In spring 2011, Wanda Diaz Merced spent time at the Harvard-Smithsonian Center of Astrophysics, doing research for her doctoral dissertation at Glasgow University, Scotland. Wanda, who is blind, has been interested in sonification as a data analysis tool: how sonification might help scientists, even those who can see, detect patterns in large amounts of seemingly random astrophysical data. She used sonified X-ray data from EX Hydrae that have been collected by the Chandra X-Ray Observatory as it is written on the webpage. A wellknown example is the Geiger Counter indicating levels of radiation. Wanda used the software $x$ Sonify, which was developed at NASA by Anton M. Schertenleib and Robert M. Candey, for sonifying the X-ray data. The software is an opensource and free and can be accessed on the NASA webpage. (5)

For the project New Europe, the X-ray analysis of mineral stones was made in collaboration with Ruđer Bošković Institute in Zagreb Croatia. Two types of quantum mechanics were used: X-ray 
powder diffraction (XRPD) which deals with particle analysis, determination of chemical and crystallographic properties, and a high-resolution scanning electron microscope FESEM.

FESEM has recorded these extreme close-up images of stones that clearly show how minerals are very contrasted.

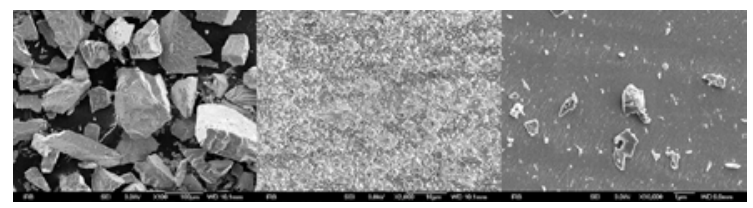

Figure 4: FESEM - extreme close-up images of three different mineral stones

X-ray analyses are expressed in numbers. The higher the peak the more precious the stone is with metal elements. The highest peak is visible from Gold Pyrite. Numbers (analysis) are expressed with a blue line which was used for converting the values into sound and represent the value of the mineral stone. The green line represents the difference between the calculated and measured diffraction images.

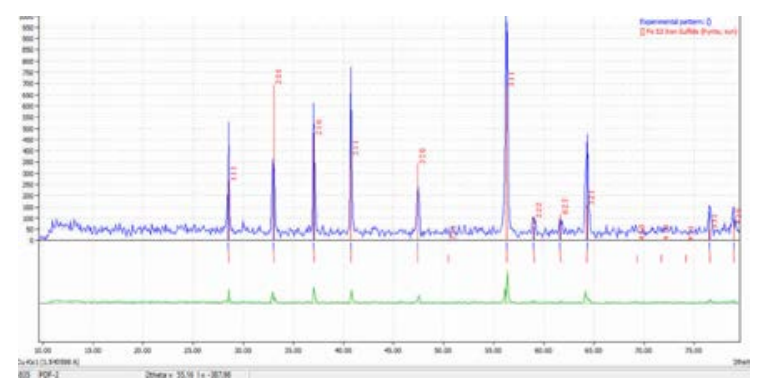

Figure 5: XRPD, X-ray powder diffraction analysis; presented numbers in diagram; Gold Pyrite FeS2 mineral stone

I used two types of transmissions to express the sound of mineral stones. One was Photo Sounder, a software by Michel Rouzic the software maker, and the other is a Musical Algorithm made by Professor Jonathan M. Middelton.

PhotoSounder is the software made for downloading on MacOs, Windows or Linux. With the software, it is possible to change speed, sound frequencies, image resolution and other possibilities for transformation of image and sound. The software was made to read the image and convert it to sound. Before any processing, I had to prepare diagrams and make a clear image of the line as it's shown - like a sound wave. During the processing from image to sound, soundwaves are color-coded by frequencies. Red is the deepest, green and blue are the highest. The results of the conversions are very deep frequency sounds which is typical from an artistic aspect. To listen to the audio files, I recommend studio headphones or a high-quality audio system with subwoofer.

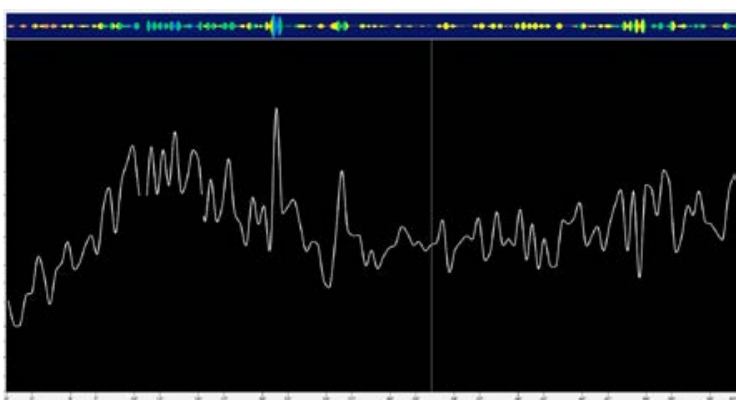

Figure 6: FESEM - extreme close-up images of three

Musical Algorithm is an online software where you have to place numbers that play with

- pitch

- duration

- instrument

etc. As the author says, the website has interactive tools that provide a unique learning experience for users, regardless of their musical training. Students of music composition can explore algorithmic composition, while others can create musical representations of models for the purpose of aural interpretation and analysis. The experiment results with a not so harmonious music ie sounds in the piano version. For example, avant-garde composers have experimented with aleatoric music which in some elements of the composition is left to chance. The sonified X-ray data would produce most obviously that type of music. (6)

Although everything is left to chance, in the research based art project New Europe the music sounds partly harmonious and meaningful. When put together, the deep frequency sounds and the piano version, the result is almost a meditative experience of relatively harmonious but abstract music.

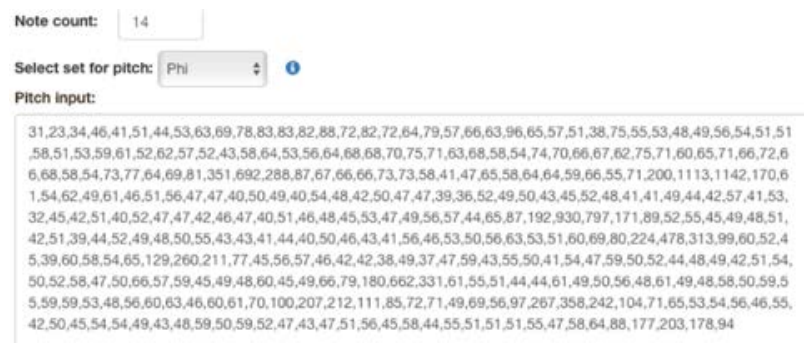

Figure 4: $X R P D, X$-ray powder diffraction analysis; presented numbers in diagram; Gold Pyrite FeS2 mineral stone

\subsubsection{Audio files}


(i) Silver Galena mineral stone https://soundcloud.com/moon-soundart/the-sound-of-mineral-stonegalenamix2019

(ii) Black Sphalerite mineral stone https://soundcloud.com/moon-soundart/the-sound-of-mineral-stone-blacksphalerite-mix

(iii) Gold Pyrite mineral stone https://soundcloud.com/moon-soundart/the-sound-of-mineral-stone-goldpyritemix

\section{CONCLUSION}

This is a sustainable piece of art which can simultaneously be enjoyed as an audio file and as a visual with different reflections and lighting on the reliefs. The main characteristics of the project New Europe are:

- a poetic outcome from laboratory X-ray analysis.

- $\quad$ sound as an unseen dimension of the stones - an untouchable medium.

- metal-based mineral stones have many beneficial material properties including energetic and healing properties which can have an impact on human development.

Humans are made to be connected with nature and are in balance between nature and technology. In the future, who knows what nature can bring, what we can discover which will makes us evolve, think differently. Our mindset will vastly depend on production and vice versa. The future of our civilisation remains unknown.

\section{REFERENCES}

Kruse C. (2015) Splitting the heavens: 4 real swords made of meteorites (Online). Available at https://www.ripleys.com/weird-news/meteoriteswords/ (Accessed: May 25, 2015) (1)

Fisher M. (2010) Why We Did Evolve Imagination? (Online). Available at https://www.theatlantic.com/technology/archive/2 010/08/why-did-we-evolve-imaginations/340279/ (Accessed: August 18, 2010) (2) (3)

Timothy Williamson (2010) Reclaiming the Imagination (Online). Available at https://opinionator.blogs.nytimes.com/2010/08/1 5/reclaiming-the-imagination/ (Accessed: August 18, 2010) (4)

Book: Asma S. T. (June 21, 2017) The Evolution of Imagination, $1^{\text {st }}$ Edition. Publication: University of Chicago Press

Book: Dr. Prrimavesi A., (August 26, 2000). Sacred Gaia, $1^{\text {st }}$ Edition. Publication: Routledge

Book: Davies J. (June 21, 2017) The Birth of the Anthropocene, 1st Edition. Publication: University of California Press

L. Diaz Merced W. (2011) Star Songs - from Xrays to music (Online) Available at https://www.cfa.harvard.edu/sed/projects/star_so ngs/index.html (5) (6)

Zelenika M. M. (2017) Available at Author's website http://www.martinazelenika.com/portfolio/neweurope-1/ 